DOI: 10.12957/demetra.2015.16117

\title{
A sujeição aos padrões corporais culturalmente construídos em mulheres de baixa renda
}

\section{Subjection to culturally constructed physical standards in low-income women}

\author{
Manoel Antônio dos Santos' \\ Rosa Wanda Diez Garcia ${ }^{2}$ \\ Marília Liotino dos Santos ${ }^{2}$ \\ 1 Universidade de São Paulo, Departamento de \\ Psicologia, Faculdade de Filosofia, Ciência e Letras \\ de Ribeirão Preto. Ribeirão Preto-SP, Brasil. \\ 2 Universidade de São Paulo, Departamento \\ de Clínica Médica, Faculdade de Medicina de \\ Ribeirão Preto. Ribeirão Preto-SP, Brasil. \\ Correspondência / Correspondence \\ Manoel Antônio dos Santos \\ E-mail:masantos@ffclrp.usp.br
}

\section{Resumo}

A obesidade feminina é um dos problemas nutricionais mais preocupantes da atualidade, com maior prevalência em mulheres com baixo nível socioeconômico. A percepção social do fenômeno da obesidade se alterou significativamente no decorrer dos tempos. Assistimos a uma sujeição contemporânea a padrões corporais culturalmente impostos e socialmente construídos, prevalecendo o imperativo estético que elege a magreza e o corpo esbelto como padrão a ser alcançado por todas as mulheres. Isso se torna particularmente perverso nas mulheres de baixa renda, devido à "ética alimentar" que norteia suas ações, segundo a qual as pessoas devem ser educadas a gostar de tudo, sendo que o ato de comer é mais valorizado do que a própria comida. Este artigo se justifica pela relevância de compreender as transformações na imagem valorizada do corpo feminino, a partir de estudos de autores que abordam o problema da obesidade em mulheres de baixo nível socioeconômico. O objetivo do estudo é refletir sobre a sujeição contemporânea aos padrões corporais culturalmente construídos, ao examinar como eles incidem em mulheres de baixa renda. Os achados permitiram desvelar o sofrimento gerado pela insatisfação corporal que aflige as mulheres pobres, uma vez que o acesso aos bens e serviços para transformar o corpo está distante de suas possibilidades financeiras. Para lidar com a frustração que inevitavelmente se instala, o prazer centrado demasiadamente na comida é exacerbado. É a possibilidade que a mulher encontra de dar expressão à frustração, ao mesmo tempo que garante a fruição de um prazer imediato.

Palavras-chave: Obesidade. Transição Nutricional. Pobreza. Estilo de vida. Comportamento Alimentar. Estética. 


\section{Abstract}

Female obesity is one of the most worrying nutritional problems nowadays, with higher prevalence in women with low socioeconomic status. The social perception of the phenomenon of obesity has significantly changed throughout the ages. There is a contemporary subjection to physical standards culturally imposed and socially constructed, prevailing the aesthetic imperative that elects thin and slender body as the standard to be achieved by all women. This becomes particularly perverse in low-income women because of "food ethics" that guides their actions, according to which people should be educated to like everything, and the act of eating is valued more than their own food. This article is justified by the importance of understanding the changes in the enhanced image of the female body, from studies of authors who address the problem of obesity in women of low socioeconomic status. The aim is to reflect on the contemporary subjection to physical standards culturally constructed and how they affect low-income women. The findings reveal the suffering caused by body dissatisfaction that afflicts poor women, since the access to goods and services to transform the body is far from your financial possibilities. To deal with the frustration that inevitably sets in, the pleasure too focused on food is exacerbated. It is the possibility that women find out to give expression to frustration and at the same time ensure the provision of immediate pleasure.

Key words: Obesity. Nutritional Transition. Poverty. Lifestyle. Feeding Behavior. Esthetics.

\section{Introdução}

Sobrepeso e obesidade são condições definidas como acúmulo anormal ou excessivo de tecido adiposo, que representa um risco à saúde. ${ }^{1}$ Um indivíduo é considerado obeso quando seu índice de massa corporal (IMC) é superior a $30 \mathrm{~kg} / \mathrm{m}^{2}$.

Estimativas recentes da Organização Mundial da Saúde mostram que, em 2014, mais de 1,9 bilhão de adultos apresentavam sobrepeso, dos quais 600 milhões estavam obesos. No total, cerca de $13 \%$ da população mundial adulta preenchia critérios para obesidade, $15 \%$ das mulheres e $11 \%$ dos homens, e 39\% da população mundial adulta apresentava sobrepeso, o que corresponde a $40 \%$ das mulheres e $38 \%$ dos homens. A prevalência mundial de obesidade mais do que duplicou 
entre os anos de 1980 e 2014, a tal ponto que a maioria da população mundial vive atualmente em países onde o sobrepeso e a obesidade matam mais pessoas do que o baixo-peso. ${ }^{1}$

Acompanhando essa tendência mundial, a prevalência de obesidade na população brasileira tem aumentado dramaticamente nas últimas quatro décadas. Esse fenômeno, reconhecido em todo o mundo contemporâneo, é resultado de uma combinação de múltiplos fatores, como o processo acelerado de urbanização, industrialização e estilo de vida sedentário, que configuram a transição nutricional. Desse modo, fatores como práticas alimentares inadequadas e baixo nível de atividade física são apontados como determinantes do crescimento das taxas de sobrepeso/ obesidade no Brasil. Estima-se que a metade da população brasileira esteja com sobrepeso e que cerca de $16 \%$ esteja obesa. ${ }^{2}$

Se por um lado se evidencia um crescimento epidêmico da obesidade, especialmente nos países industrializados, ${ }^{1}$ no contrafluxo desse movimento pode-se perceber o surgimento de uma sociedade lipofóbica, que estigmatiza os obesos, ${ }^{3}$ associando a obesidade a valores morais negativos. ${ }^{4}$

O movimento da globalização, que acompanha a expansão do sistema capitalista na sua vertente mais recente, tem impacto direto na cultura alimentar, resultando em mudanças significativas no padrão alimentar do homem urbano. ${ }^{5}$ Essas mudanças no padrão de alimentação precisam ser compreendidas em sua complexidade, ${ }^{6}$ o que inclui considerar a multidimensionalidade de determinantes, como os fatores sociais, culturais e psicológicos que atravessam a alimentação. A obesidade não acarreta apenas prejuízos à saúde, mas produz alterações psicológicas e sociais significativas para a pessoa obesa, tais como diminuição da autoestima, depreciação da qualidade de vida, percepção negativa do próprio corpo e identidade social deteriorada. ${ }^{2}$

Entre as mulheres, em particular naquelas de baixa renda, a submissão a certos padrões estéticos impossíveis de serem alcançados (ou incompatíveis com a saúde) torna-se ainda mais perverso, o que torna o "peso social" da obesidade particularmente intenso e intolerável para esse grupo social. Isso se expressa nos apelos sociais pela magreza e no cultivo obsessivo de um ideal de corpo esbelto. A assunção do corpo magro como padrão de beleza incontestável conduz a uma série de problemas graves, que afetam a saúde física e mental, sendo os mais extremos os transtornos alimentares, como anorexia e bulimia nervosas.

Pode-se questionar se o processo de aumento do peso corporal no contexto da mulher de baixa renda não estaria relacionado às mudanças observadas no ciclo de vida. Assim, é interessante considerar o aspecto geracional do aumento de peso e da obesidade. Essas questões balizam o desenvolvimento do presente estudo.

Considerando esses pressupostos, este estudo teve por objetivo refletir sobre a sujeição contemporânea aos padrões corporais culturalmente construídos, ao examinar como eles incidem em mulheres de baixa renda. 


\section{Método}

Para alcançar o objetivo proposto, optou-se por um estudo reflexivo, fundamentado na literatura dedicada à temática.

\section{Análise e desenvolvimento do tema}

Estudos epidemiológicos evidenciam que a obesidade feminina se configura como um dos problemas nutricionais mais preocupantes da atualidade, com maior prevalência em mulheres com baixo nível socioeconômico. ${ }^{7}$ Ao avaliar o estilo de vida como fator de risco para a prevalência da obesidade entre mulheres brasileiras de baixa renda, foram encontradas $31,9 \%$ com sobrepeso e 22,2\% com obesidade. Houve diferença estatisticamente significativa entre o IMC e as variáveis "renda" e "idade". ${ }^{8}$ Os autores constataram consumo excessivo de lipídios e insuficiente em carboidratos e fibras; $88,9 \%$ das mulheres eram sedentárias. O estudo concluiu que a obesidade entre as mulheres pobres expressa, na realidade, os novos contornos da pobreza urbana, estando associada à baixa renda, ao sedentarismo e à cultura alimentar.

Vista em uma perspectiva histórica, a percepção social do fenômeno da obesidade se alterou significativamente no decorrer dos tempos, o que pode ser resumido na seguinte máxima: o que era bom tornou-se feio e, posteriormente, o que era feio tornou-se maligno. ${ }^{9}$ Entende-se, desse modo, a construção social do obeso maligno. Esse percurso, que progrediu do "bom" ao "feio", e do "feio" ao "maligno", como se coloca na contemporaneidade, mostra o quanto a obesidade, como categoria social, está sujeita à ação de julgamentos morais. Na atualidade, o indivíduo obeso é, frequentemente, visto como alguém moralmente frouxo, fraco de caráter e indisciplinado, uma pessoa "sem vergonha na cara", que sucumbe aos impulsos mais primitivos e que, no limite, busca a ruína da própria saúde e autodestruição. Por outro lado, assistimos a uma sujeição contemporânea aos padrões corporais culturalmente impostos e socialmente construídos.

Assim, pode-se dizer que a demonização atual do corpo obeso atende ao mesmo imperativo cultural que elege a esbelteza e o corpo "enxuto" como padrão a ser alcançado por todos. Não deixa de ser irônico que a mesma sociedade que se esmera em condenar a obesidade como vetor de inúmeras doenças, desenvolve enorme tolerância em relação aos corpos esquálidos, como também aos corpos "sarados" e anabolizados, que a bem da verdade podem ser tão ou mais doentios do que os obesos. 


\section{Autoimagem e (in)satisfação com o próprio corpo}

Estudo brasileiro que abrangeu 100 mulheres de 20 a 50 anos de camadas de baixa renda, com IMC classificado como obesidade graus I e II, investigou a satisfação e idealização corporal. ${ }^{10}$ Os dados obtidos fornecem pistas valiosas para mostrar a força com que certos modelos e padrões impostos influenciam negativamente na autoestima dessas mulheres de baixo nível socioeconômico. A autoimagem é constituída pela percepção, ou seja, pelas impressões assimiladas pelos sentidos, associadas à atribuição de significados. ${ }^{11}$ Esse conjunto de informações, captadas pelos órgãos dos sentidos e incrementadas pelos significados que recebem, calibra a percepção, associando conhecimento, memória e cognição. ${ }^{12}$ Portanto, a interação entre esses diversos componentes molda a percepção do indivíduo, que também é mediada por fatores sociais.

Comparar a si mesmo com outros indivíduos auxilia a consolidar padrões de referência que, nesse caso, se traduzem pela construção do conceito de peso e de corpo idealizado. ${ }^{13}$ Indivíduos que convivem com alta prevalência de obesidade percebem menos seu excesso de peso, determinado pela normalidade epidemiológica. A autoimagem é ajustada pela percepção, construída pelas interações sociais e pelos padrões culturais. ${ }^{13-15}$ Decorre dessa capacidade perceptiva a satisfação de pertencer aos padrões apreciados de beleza e de tamanho corporal, e o contrário, a insatisfação de estar aquém dos valores apreciativos.

Se não houvesse exposição à norma que regula como deve ser o corpo e a beleza, nossa percepção seria basicamente modulada pelo que é visto nas ruas e constatado pelas estatísticas. Consequentemente, a satisfação com o corpo seria mais influenciada pela predominância do que é comum. Todavia, parece que a imagem propagada informa mais do que a realidade observada.

O presente estudo reflexivo se concentra na relação entre a força desses constructos de corpo idealizado com a análise dos dados dos estudos com mulheres de baixa renda com obesidade. ${ }^{3}$ No estudo de Liotino-Santos, ${ }^{10}$ o ganho de peso no último ano, referido pela maioria das mulheres, foi excessivo e acelerado quando comparado a outras populações. ${ }^{16-18} \mathrm{Em}$ média, o aumento de peso referido foi de 10,5 kg entre as mais novas (geração 1980/1990) e 7,7 kg entre as mais velhas (geração 1960/1970). Práticas da adolescência podem ter a motivado o ganho de peso agudo e rápido refletido na geração 1980/1990, como aumento no consumo de açúcar simples, alimentos industrializados, redução do consumo de frutas e hortaliças, hábito de omitir refeições, sedentarismo e aumento de atividade que exigem menor gasto energético como ver televisão, jogar videogame ou usar o computador. ${ }^{19,20}$

Ainda de acordo com os resultados do estudo de Liotino-Santos, ${ }^{10}$ as participantes referiram grande insatisfação com seu peso, já que apenas $2 \%$ das mulheres da geração mais nova e $8 \%$ da geração mais velha estavam satisfeitas com seus pesos. Comentários negativos sobre o peso foram 
referidos por, respectivamente, 84 e $89 \%$ das participantes. Comentários negativos em relação ao peso contribuem para o ganho de peso, já que mulheres com excesso de peso consomem até três vezes mais calorias quando expostas a conteúdos negativos relacionados a estereótipos de peso em relação àquelas que não foram expostas a esses conteúdos. ${ }^{21}$

O mencionado estudo, ${ }^{10}$ ao historiar o ganho de peso das participantes, mostra que as mulheres mais velhas referiram que começaram a ganhar peso mais tardiamente do que as mais novas. As mulheres da geração 1980/1990, que hoje são classificadas com obesidade grau I ou II, podem estar no processo de ganho de peso seguindo a linha da progressão do peso durante a vida. Já nas mulheres mais novas, esse ganho de peso foi mais rápido. Gravidez foi o motivo alegado para o ganho de peso por $56 \%$ das mulheres mais velhas, além de problemas emocionais (13\%) e doença ou tratamento médico (12\%). Para as mais novas, esse ganho de peso ocorreu, principalmente, em decorrência da gravidez (29\%) e de doença ou tratamento médico (25\%), seguidos de casamento (10\%), problema emocional (10\%) e por ficar em casa (10\%). A geração de mulheres mais velhas relatou maior ganho de peso durante a gestação do que as mais novas. ${ }^{10}$

Também relataram terem sido magras ou normais aos 20 anos $79 \%$ das mulheres mais velhas e 52\% das participantes mais novas. Todavia, o peso referido por elas aos 20 anos foi semelhante. Do total, $86 \%$ das mais velhas e $64 \%$ das mais novas se consideraram magras ou normais no casamento. As diferenças de peso representam um ganho médio referido de $21,9 \mathrm{~kg}$ para as mais novas, e 28,2 kg para as mais velhas. Essas diferenças em relação à idade do casamento foram, em média, de 24,4 kg e 29,8 kg. ${ }^{10}$ Uma das razões para a maior percepção da obesidade pelas mulheres mais novas pode ser o maior contato com serviços de saúde, capazes de diagnosticar e alertar sobre o aumento de peso. Estudos mostram a influência da informação do diagnóstico de excesso de peso por profissionais de saúde e a influência exercida na autopercepção correta do estado nutricional. ${ }^{22,23}$ Por outro lado, a percepção mais precoce da obesidade pode ser explicada pelo fato de ganharem peso mais cedo e de, atualmente, a sociedade estar mais atenta à obesidade.

Em resumo, as participantes do estudo se mostraram descontentes com seu corpo. Estavam infelizes, pois não gostavam, nem queriam manter o corpo que tinham. Estavam obesas e ganhando muito peso, em média $10 \mathrm{~kg}$ no último ano. As mais jovens casaram-se com um peso maior do que as da geração mais velhas. Ou seja, alcançaram esse peso acima do desejado mais cedo do que se observou nas mulheres mais velhas, o que indica que a obesidade parece estar "se adiantando" nesse grupo social. Além dessa tendência, elas posteriormente continuaram ganhando peso após o casamento e as gravidezes.

Seguir uma dieta é algo visto como desafiador, no limite do impossível. Silva ${ }^{24}$ chama a atenção para a ética alimentar peculiar às de baixa renda. O comportamento de comer tudo e de tudo é 
parte da disciplina alimentar popular, determinado pela regra moral que condena o desperdício. As pessoas são educadas a gostar de tudo. Em geral, o ato de comer é mais valorizado do que a própria comida. Esses achados mostram com nitidez que alimentação e identidade cultural caminham juntas. ${ }^{25}$

Além disso, por terem baixo poder aquisitivo, essas mulheres não podem "comprar" aquele corpo ideal que desejam, com seus atributos que estão na moda, como seios (próteses mamárias) de determinado tamanho e formato. Certamente, o mercado dispõe de uma rede de profissionais de diferentes especialidades, que formatam o corpo feminino conforme as tendências da moda. Por exemplo, para vender as presumíveis maravilhas que podem ser alcançadas com os suplementos alimentares ou ao se submeter a uma lipoescultura, há aqueles que projetam uma foto da pessoa "gordinha" e, sem seguida, simulam, em outra foto, a pessoa "sarada", ou seja, como ela supostamente ficaria depois da intervenção.

\section{O culto apolíneo ao corpo retrata a sociedade e o tempo em que se vive}

O culto ao corpo está intimamente associado à época e à sociedade em que se vive. ${ }^{26} \mathrm{O}$ que cada contexto social e período histórico elegem como formato ideal do corpo varia enormemente ao longo da história, uma vez que os padrões estéticos consagrados são condicionados pelas características destacadas como apreciáveis em cada momento. Ao passar em revista as mulheres que em suas épocas ficaram conhecidas como padrões de beleza, algumas observações interessantes se impõem. No Brasil dos anos 1950, a Miss Brasil Martha Rocha perdeu a disputa do concurso de Miss Universo de 1954 supostamente porque tinha "duas polegadas a mais". O volume adicional estava concentrado nos quadris e fez a baiana ser superada pela "delgada ianque" Miriam Stevenson. O episódio acabou imortalizado na marchinha de carnaval "Duas polegadas", gravada pela própria Martha Rocha: "Por duas polegadas a mais / passaram a baiana pra trás. / Por duas polegadas, e logo nos quadris, / Tem dó, tem dó, seu juiz. / Martha, Martha, não liga mais pra isso não. / Martha, Martha, ninguém tem o seu violão."

Ter ficado com o vice-campeonato no concurso de Miss Universo não impediu Martha Rocha de ser alçada ao estrelato e de se tornar referência de beleza no Brasil, com seus olhos azuis e cabelos loiros curtos e cacheados, e seu corpo robusto, com formas generosas, bem distantes do padrão cadavérico que domina o imaginário social da atualidade.

Na década seguinte, um novo padrão de beleza feminina viria a se impor, sacudindo a sociedade ocidental. Twiggy, nome artístico de Lesley Lawson, nascida em Londres, apareceu nos anos 1960 como uma das primeiras supermodelos do mundo. Sua imagem quase andrógina, esculpida em um corpo pequeno e extremamente magro, contribuiu para fixar no imaginário social a imagem 
das modelos hipermagras, que viriam a dominar as passarelas da moda nas décadas seguintes. As fotos dessa época em que viveu o auge de sua carreira evidenciam um ar de profunda tristeza. A sensação de desamparo que sua face irradiava é reforçada pelos cabelos loiros muito curtos e os olhos enormes realçados com rímel e cílios postiços. Essa figura tornou-se um ícone da moda e estilo, servindo de inspiração para milhões de mulheres ocidentais, de todas as latitudes e longitudes do planeta. ${ }^{1}$ Interessante observar que, aos 21 anos, Twiggy encerrou precocemente sua bem-sucedida carreira de modelo para se dedicar à música, ao cinema e ao teatro. Declarou, na época, que "ninguém pode ser um cabide de roupas para sempre". Posteriormente, comandou seu próprio talk-show, Twiggy’s People.

Twiggy consagrou a imagem da mulher sem curvas, "sem peito" e sem formas voluptuosas, como era o padrão de mulher nas épocas anteriores. A ruptura estabelecida com o padrão anterior de beleza feminina era evidente, mas ainda estava longe de ter a disseminação midiática que observamos nas décadas seguintes, com a sacralização do corpo esbelto, hipermagro e esquálido. Antes disso, contudo, nos anos 1970 vivemos uma transição. A atriz estadunidense Jane Fonda estabeleceu um padrão de mulher com o olhar permanentemente colocado na balança, adepta de exercícios físicos intensos e da busca da magreza. A atriz, que havia caído no ostracismo, passou a produzir vídeos em que aparece de malha de ginástica ensinando exercícios aeróbicos para as mulheres. Mais de duas décadas depois, em sua autobiografia, a atriz confessou que era profundamente infeliz nessa época das aulas de ginástica e que sofria de bulimia nervosa. Jane relata que se conscientizou de que passou a vida tentando agradar os homens de sua vida buscando um corpo irreal, que supostamente agradaria seus parceiros, evitando assim a rejeição.

Nascia, assim, o padrão da mulher que viria a surgir nas décadas posteriores, a mulher fabricada em academia, escrava de exercícios físicos e dependente de drogas anorexígenas, com o padrão anoréxico/cadavérico sendo elevado ao posto de ideal de ser da mulher a partir da década de 1970. Até que chegamos no padrão atual das "paniquetes" do programa de TV, que entroniza a mulher bombada, de abdômen sarado e glúteos inflados e aprumados. Percebe-se, assim, que a idealização de um certo padrão corporal é a contraface da imposição de um ideal de corpo construído culturalmente.

O que está em questão, na presente reflexão, é de que modo esses padrões, igualmente idealizados e suprarreais, incidem sobre o imaginário das mulheres de baixa renda. Ou seja, até que ponto a imagem da magreza ambulante ("cabide de roupas") sai da passarela para se instalar nos espaços recônditos das famílias que têm filhas adolescentes. Mais do que uma mudança de cenário, trata-se de um modelo idealizado de corpo que se dissemina, generalizando e dissipando esse ideal a ser absorvido pela sociedade. 


\section{A construção social da insatisfação com o corpo na mulher de baixa renda}

A percepção que os indivíduos pertencentes a cada classe social têm sobre o seu próprio corpo é um dos fatores que medeiam a percepção dos efeitos da alimentação sobre si mesmo e sua relação com a saúde e a beleza. Silva, ${ }^{24}$ a partir da concepção de Bourdieu,${ }^{27}$ considera que as camadas de baixa renda priorizam a força do corpo - força de trabalho - em detrimento da forma corporal. Isso é válido para o comer masculino, mas não pode ser generalizado para as mulheres. Além disso, a literatura mostra que há grande dinamicidade e heterogeneidade de perspectivas nas camadas de baixo nível socioeconômico. Na análise dietética da população feminina, é preciso considerar o papel da mulher no contexto alimentar da família, pois cabe a ela a responsabilidade de nutri-la no ambiente doméstico. ${ }^{24}$

É preciso considerar também que a sobrecarga do trabalho doméstico, que inclui as tarefas relacionadas ao preparo das refeições, é maior entre mulheres de baixa renda. Além de exercerem funções remuneradas no contexto extradoméstico, não podem contar com o apoio da empregada doméstica, nem têm à sua disposição uma série de eletrodomésticos que contribuem para reduzir a sobrecarga de trabalho. Em relação à última afirmação, é preciso considerar que, nos últimos anos, foram implementadas políticas de incentivo ao consumo das camadas de baixa renda, e que o aumento do consumo de bens duráveis por essa parcela da população foi amplamente alardeado pelo governo como conquista produzida por essas políticas. Também se observa nas famílias de baixa renda que a preparação de pratos tende a ser menos individualizada. Quando as mulheres tentam seguir uma dieta, terão mais trabalho para preparar uma dieta específica, sem contar a resistência dos homens para aceitarem a modificação do cardápio. ${ }^{24}$

Como era de se esperar, após a entronização do ideal de formato corporal, uma profusão de serviços foi criada no campo da estética física, medicina, educação física e cosmetologia, com oferta de inúmeras possibilidades concretas de intervir no corpo, remodelando-o, corrigindo-o e reeducando-o incessantemente, seguindo uma estética própria dos corpos modificados. Surge, assim, o que chamamos de "desenho do corpo construído" pela via das cirurgias plásticas, das dietas milagrosas e da malhação frenética em academias que prometem esculpir os corpos de acordo com os estereótipos corporais.

Instala-se no contemporâneo uma sólida mercantilização do corpo. Em outras palavras, dissemina-se a ideia de que se tornou possível comprar o corpo que se deseja. A sociedade tecnológica promete colocar ao alcance das mãos - evidentemente, daqueles que têm poder de compra - um farto arsenal de transformação corporal. Essa noção aparece em blagues, como o daquela mulher que diz: "Sim, esses peitos são meus. Eu os comprei, então são meus". 
Além do mercado da cirurgia plástica com finalidade estética, a rendosa indústria cosmética se aproveita da voga da mercantilização do corpo para proporcionar opções de metamorfose da aparência física ao alcance das mãos. Há mudanças constantes de shape, com a criação de modelos corporais artificiais e muitas vezes extremamente desumanos. Além disso, nos dias de hoje a obesidade está fortemente sujeita à medicalização, especialmente a partir do desenvolvimento de tecnologias médicas, que aperfeiçoaram as técnicas de cirurgia bariátrica. ${ }^{9}$ Intervenções radicais, como a cirurgia bariátrica, despontam como uma espécie de panaceia universal, que promete erradicar rapidamente as condições que perpetuam o ganho de peso, sem eliminar os fatores causais. Para o indivíduo que atravessou parcela importante de sua vida lutando contra a obesidade, perceber uma perspectiva de transformar sua condição de obeso sem a exigência de uma desgastante rotina de controle alimentar, associado à prática regular de exercícios físicos, surge como a possibilidade de redenção tão esperada.

Estamos nos referindo à venda de determinado padrão corporal criado artificialmente enquanto imagem glorificada do corpo feminino. ${ }^{26,27}$ As mudanças rápidas de padrões desnaturalizados, construídos midiaticamente e vendidos em pacotes de diferentes segmentos de plástica a hormônios, academias e dietas. Um exemplo das mudanças do padrão estético pode ser buscado na moda atual que pontifica que homens e mulheres devem estar sem pelos. Eles impúberes, elas sem os pelos pubianos.

Os achados dos estudos realizados com mulheres de baixa renda permitem desvelar o sofrimento gerado pela insatisfação corporal que as aflige. Se há, por um lado, uma insatisfação com o corpo, o acesso aos bens e serviços para transformá-lo está indisponível. As mulheres pobres não dispõem de meios para consumir o corpo que está à venda no balcão social, com o qual acreditam que poderiam alcançar um formato idealizado. Por isso padecem em longas filas de espera dos hospitais públicos aguardando por uma vaga - por exemplo, para se submeterem à cirurgia bariátrica. Mulheres pobres não dispõem de meios para consumir a tecnologia de transformação corporal com a qual acreditam que poderiam alcançar um formato corporal idealizado. A maioria esmagadora permanecerá ao largo dessa realização. Para lidar com a frustração que, inevitavelmente, se instala, o prazer demasiadamente centrado na comida em nossa sociedade pode ser exacerbado. É a possibilidade que a mulher encontra de dar expressão à sua frustração, ao mesmo tempo que consegue obter o alívio proporcionado pela fruição do prazer imediato.

A partir das reflexões desenvolvidas neste estudo, postulamos que a insatisfação é produzida sistematicamente, de modo a assegurar que as mulheres, especialmente aquelas pertencentes às camadas de baixo nível socioeconômico, permaneçam sentindo que estão sempre aquém do padrão valorizado como ideal, o que perpetua o ciclo da insatisfação que as aprisiona. Com isso, as mulheres ficam mais subjugadas e imobilizadas, até porque estão lutando contra um inimigo que, ao fim e ao cabo, está "dentro" delas. 
Não há um padrão mínimo de satisfação, e isso cumpre um propósito na manutenção da máquina da mercantilização. Só um corpo insatisfeito pode consumir incessantemente. Logo, não haver um limite claramente discernível é a estratégia de manutenção de mulheres permanentemente insatisfeitas, desmobilizadas, inseguras e confinadas em seu drama humano.

É importante levar em consideração essa configuração de fatores quando se analisam os marcos do ciclo vital de aumento corporal para a mulher. O profissional de saúde precisa conhecer como evolui a mudança corporal e quais as variáveis socioeconômicas que influenciam essas alterações, considerando ainda a centralidade do corpo como elemento de reprodução da feminilidade. ${ }^{28}$

Ao tomar como referência as mulheres de baixa renda, observa-se, pelos resultados obtidos por Liotino-Santos, ${ }^{10}$ que não há uma calibração do ideal desejado quando se consideram as diferentes fases da vida. A idealização do padrão corporal permanece a mesma, independentemente da faixa etária, ou seja, a mesma exigência que é posta para uma mulher de 20 anos mostra-se forte e determinante para as demais fases. Nesse estrato social, muitas vezes a mulher é economicamente dependente do marido. Ela quer ser atraente aos olhos dele e os modelos que ela encontra na cultura em que vive cristalizam desejos, em geral, de mulheres mais novas, que estão no auge da juventude e, portanto, teoricamente com mais facilidades de alcançar o padrão valorizado. Por isso, a possibilidade de se verem frustradas é apreciável. Como o ganho de peso na mulher de baixo nível socioeconômico é crescente com o passar dos anos, a tendência é crescer também a insatisfação com o corpo.

\section{Conclusões}

O mundo contemporâneo vive um processo de transição nutricional, que resulta em uma alta prevalência de sobrepeso e obesidade na população mundial. ${ }^{4}$ De fato, na atualidade observa-se a emergência de profundas mudanças nos hábitos alimentares, com seu impacto dramático na saúde. A denominada cultura do junk food, o incremento exponencial do consumo de produtos industrializados e a disseminação dos alimentos diet/light têm trazido enormes mudanças na composição nutricional da dieta familiar.

Neste estudo, refletimos sobre a questão da insatisfação da mulher de camadas baixo nível socioeconômico com seu corpo, ao tomá-lo pelo prisma dos padrões atualmente valorizados. Propomos que é bastante elucidativo analisar esse fenômeno ao longo das décadas. Vimos que as mulheres adultas de baixa renda não fazem ajuste de seu ideal corporal de acordo com a idade, ou seja, a idealização corporal não leva em consideração os limites e possibilidades condizentes com o estágio do ciclo vital em que se encontram. Para fixarem o que consideram ser seu ideal corporal, elas se pautam mais em aspectos do contexto sociocultural, como os modelos e padrões impostos pelo discurso midiático que calibram a percepção da autoimagem e da imagem corporal. Assim, 
perde-se o senso crítico em relação aos corpos esculturais venerados incessantemente pela mídia e que se inscrevem de modo indelével no imaginário coletivo, determinando a tirania da magreza.

Como usualmente acontece, as aparências enganam e os corpos fabricados e ostentados nas capas das revistas vendidas em bancas de jornal ou nos intervalos comerciais da televisão ocultam sua inexequibilidade. São completamente irreais e inatingíveis, na medida em que traduzem o ideal de perfectibilidade e desempenho cultivado pela sociedade de consumo, e que é deslocado para o plano da forma e do peso corporais. Ou, dito de outro modo, esses corpos esbeltos representam um padrão ideal distorcido que só pode ser alcançado por meio do comprometimento da saúde física e psíquica.

Seguindo essa vertente, também identificamos neste estudo a estabilidade do padrão culturalmente valorizado do corpo feminino ao longo do tempo, o que nos leva a postular que o apelo midiático reflete os interesses comerciais de uma saúde transformada em mercadoria.

O sofrimento emocional apresentado pelas mulheres com baixo nível socioeconômico é considerável. As mulheres pobres não dispõem de meios para consumir a tecnologia de transformação corporal com a qual acreditam que poderiam alcançar um formato corporal idealizado. Para lidarem com a frustração inevitável, o prazer sensorial centrado demasiadamente na comida passa a ser exacerbado.

A sociedade que, atualmente, esculpe o ideal apolíneo de corpo nas academias e spas, condena os que se desviam da boa forma física, estigmatizando esses indivíduos como pessoas dotadas de corpos insubmissos aos padrões corporais vigentes. A construção cultural do obeso maligno mostra que a carga de se conviver socialmente com o excesso de peso é substancial e não pode ser desconsiderada, pois pode ser tão ou mais penosa do que carregar o corpo pesado. Compreender seu impacto subjetivo e existencial é parte da solução do problema.

\section{Agradecimentos}

Conselho Nacional de Desenvolvimento Científico e Tecnológico - CNPq, pela bolsa de Produtividade em Pesquisa concedida ao primeiro autor.

\section{Referências}

1. World Health Organization. Obesity and overweight. Fact sheet $n^{\circ}$ 311. Genebra: WHO; 2015. Disponível em: http://www.who.int/mediacentre/factsheets/fs311/en/

2. Mendonça CP, Anjos LA. Aspectos das práticas alimentares e da atividade física como determinantes do crescimento do sobrepeso/obesidade no Brasil. Cad. Saúde Pública 2004; 20(3):698-709. 
3. Mattos RS, Luz MT. Sobrevivendo ao estigma da gordura: um estudo socioantropológico sobre obesidade. Physis 2009; 19(2):489-507.

4. Neves AS, Mendonça ALO. Alterações na identidade social do obeso: do estigma ao fat pride. Demetra 2014; 9(3):619-63.

5. Diez-Garcia RWD. Reflexos da globalização na cultura alimentar: considerações sobre as mudanças na alimentação urbana. Rev. Nutr. 2003; 16(4):483-92.

6. Mondini L, Monteiro CA. Mudanças no padrão de alimentação. In Monteiro CA, editor. Velhos e novos males da saúde do país. São Paulo: Núcleo de Pesquisas Epidemiológicas em Nutrição e Saúde, Universidade de São Paulo; 2000.

7. Instituto Brasileiro de Geografia e Estatística. Pesquisa de orçamentos familiares 2008-2009: antropometria e estado nutricional de crianças, adolescentes e adultos no Brasil. Rio de Janeiro [Internet]. Rio de Janeiro: IBGE; 2010. [citado 23 mar. 2015]. Disponível em: http://www.ibge.gov. br/estadosat/temas.php?sigla=rj\&tema=pofantropometrica_2009

8. Franke D, Wichmann, FMA, Prá, D. Estilo de vida e fatores de risco para o sobrepeso e obesidade em mulheres de baixa renda. CINERGIS 2007; 8(1):40-9.

9. Eknoyab G. A history of obesity, or how what was good became ugly and then bad. Adv. Chronic Kidney Dis. 2006; 13(4):421-27.

10. Liotino-Santos M. Percepção da obesidade em mulheres obesas e profissionais de saúde [dissertação]. Ribeirão Preto (SP): Faculdade de Medicina de Ribeirão Preto da Universidade de São Paulo; 2012. 111 p.

11. Allport FH. The problem of perception: its place in the methodology of science. In: Allport FH. Theories of perception and the concept of structure. New York, 1955. p. 14-57.

12. Lent R. Às portas da percepção: as bases neurais da percepção e da atenção. In: Lent R. Cem bilhões de neurônios: conceitos fundamentais de neurociência. São Paulo: Atheneu, 2001. p. 557-586.

13. Johnson F, Cooke L, Croker H, Wardle J. Changing perceptions of weight in Great Britain: comparison of two population surveys. BMJ 2008; 337:270.

14. Almeida GAN, Santos JE, Pasian SR, Loureiro SR. Percepção de tamanho e forma corporal de mulheres: estudo exploratório. Psicol. Estud. 2005; 10(1):27-35.

15. Christakis NA, Fowler JH. The spread of obesity in a large social network over 32 years. New Engl J Med 2007; 357(4):370-79.

16. Williams L, Germov J, Young A. The effect of social class on mid-age women's weight control practices and weight gain. Appetite 2011; 56(3):719-25.

17. Brown WJ, Williams L, Ford JH, Ball K, Dobson AJ. Identifying the energy gap: Magnitude and determinants of 5-year weight gain in midage women. Obesity Research 2005; 13(8):1431-41.

18. Purslow LR, Young EH, Wareham NJ, Forouhi N, Brunner EJ, Luben RN, et al. Socioeconomic position and risk of short-term weight gain: prospective study of 14,619 middle-aged men and women. BMC Public Health 2008; 8:112. 
19. Fonseca VM, Sichieri R, Veiga GV. Fatores associados à obesidade em adolescentes. Rev Saúde Pública 1998; 32(6):541-9.

20. Enes C, Slater B. Obesidade na adolescência e seus principais fatores determinantes. Rev. Bras. Epidemiol. 2010; 13(1):163-71.

21. Schvey NA, Puhl RM, Brownell KD. The impact of weight stigma on caloric consumption. Obesity 2011; 19(10):1957-62.

22. Post RE, Mainous AG, Gregorie SH, Knoll ME, Diaz VA, Saxena SK. The influence of physician acknowledgment of patients' weight status on patient perceptions of overweight and obesity in the United States. Adv. Intern. Med. 2011; 171(4):316-21.

23. Yaemsiri S, Slining MM, Agarwal SK. Perceived weight status, overweight diagnosis, and weight control among US adults: the NHANES 2003-2008 study. Int. J. Obesity 2011; 35(8):1063-1070.

24. Silva LAS. O corpo, o comer e a comida: um estudo sobre as práticas corporais e alimentares no mundo contemporâneo. História: Questões \& Debates 2011; 54:287-290.

25. Maciel E. Identidade cultural e alimentação. In: Canesqui AM, Garcia RWD, organizadores. Antropologia e nutrição: um diálogo possível. Rio de Janeiro: Fiocruz; 2005. 49-55.

26. Castro AL. Culto ao corpo e sociedade: mídia, estilos de vida e cultura de consumo. São Paulo: Annablume; Fapesp; 2003.

27. Bourdieu P. La distinción: critérios y bases sociales del gusto. Madrid: Taurus; 1988.

28. Bordo S. O corpo e a reprodução da feminilidade: uma apropriação feminista de Foucault. In: Jaggar A, Bordo SR, organizadores. Gênero, corpo, conhecimento. Rio de Janeiro: Rosa dos Tempos; 1997. p. 19-38.

Recebido: $18 / 4 / 2015$

Revisado: $11 / 7 / 2015$

Aprovado: 17/10/2015 